\section{Contribuições da Análise da Conversa para os estudos sobre o cuidado em saúde: reflexões a partir das atribuições feitas por pacientes}

\author{
Contributions by Conversation Analysis to \\ healthcare studies: reflections based \\ on patients' attributions
}

\author{
1 Programa de Pós-graduação \\ em Lingüística Aplicada, \\ Universidade do Vale do Rio \\ dos Sinos, São Leopoldo, \\ Brasil. \\ Correspondência \\ A. C. Ostermann \\ Programa de Pós-graduação \\ em Lingüística Aplicada, \\ Universidade do Vale do \\ Rio dos Sinos. \\ Av. Unisinos 950, São \\ Leopoldo, RS \\ 93022-000, Brasil. \\ aco@unisinos.br
}

\begin{abstract}
This study is part of a larger research project aimed at investigating physician-patient interactions in women's health. In this article, by looking at naturalistic data, which consists of 144 fully transcribed audio recordings of face-to-face interactions between gynecologists/obstetricians and female patients, we propose to: (1) present the theoretical and methodological approach of Conversation Analysis to health studies in Brazil; (2) discuss how Conversation Analysis can reveal how "macro" questions (e.g. National Policy for the Humanization of Healthcare) are (or are not) translated into interactional practices at the " $m i$ cro" level and, thus, emphasize the issues of language and communication, only briefly discussed in the HumanizaSUS documents; and (3) analyze how a specific interactional phenomenon, "attribution" (i.e. voluntary explanations about the possible causes of their problems), might describe ordinary and concrete humanization practices in healthcare services.
\end{abstract}

Physician-Patient Relations; Women's Health; Humanization of Assistance
Ana Cristina Ostermann 1

Joseane de Souza 1

\section{Introdução}

A importância da comunicação entre profissionais da saúde e pacientes tem sido o foco crescente de estudos e debates recentes nas arenas nacional 1,2,3,4,5 e internacional 6,7,8,9,10,11,12. Conforme relatam Ostermann \& Silva 5 , chama igualmente a atenção o crescente número de publicações em periódicos internacionais interessados na formação de profissionais da saúde sobre estudos acerca da ordem microinteracional (i.e., estudos das interações que se dão nos atendimentos em si) 8,13,14. A partir disso, observa-se que, cada vez mais, o cenário mundial demonstra preocupação com uma formação mais integral dos profissionais de saúde, deslocando o eixo de atenção do o que fazer (conhecimento técnico-científico), de forma a também incorporar o como fazer (a fim de contemplar o plano da comunicação profissional/cliente).

No Brasil, no entanto, pesquisas na área da saúde que se dedicam à fala-em-interação enquanto lócus constitutivo dos atendimentos em saúde ainda são escassas. Enquanto que são relativamente comuns pesquisas sobre a qualidade de atendimentos na saúde 15,16,17,18 que utilizam questionários ou entrevistas post-factum com pacientes e/ou profissionais (i.e., entrevistas sobre suas percepções de como foram os atendimentos), ainda são praticamente inexistentes investigações com dados naturalísticos (i.e., que investigam o atendimento de saúde em si e as ne- 
gociações que se dão entre os participantes nestes atendimentos).

Compreende-se até certo ponto essa situação, na medida em que, em locais de escassos recursos financeiros, as precariedades materiais e técnicas ganham maior ênfase. Contudo, sabese que uma comunicação eficaz entre profissional da saúde e paciente pode contribuir para a qualidade do cuidado e do tratamento e para a melhora da saúde. Em outras palavras, uma interação mais cultural e lingüisticamente sensível entre profissionais da saúde e pacientes pode melhorar os resultados em termos de prevenção, diagnóstico, tratamento e gerenciamento de problemas de saúde 1 , bem como contribuir para a resolução do problema da não-adesão ao tratamento.

A Política Nacional de Humanização do SUS (HumanizaSUS) 19, iniciativa do Ministério da Saúde, ainda que de forma bastante breve, aponta para o valor da linguagem, da interação e do diálogo no processo de humanização. Isso na verdade acontece desde o documento inicial do Programa Nacional da Humanização, de 2000, até a versão vigente da Política Nacional de $\mathrm{Hu}$ manização do Ministério da Saúde, de 2004, conforme pode ser observado a seguir.

"Então, o que é humanizar? Entendido assim, humanizar é garantir à palavra a sua dignidade ética. Ou seja, o sofrimento humano e as percepções de dor ou de prazer no corpo, para serem humanizados, precisam tanto que as palavras que o sujeito expressa sejam reconhecidas pelo outro, quanto esse sujeito precisa ouvir do outro palavras de seu reconhecimento. Pela linguagem fazemos as descobertas de meios pessoais de comunicação com o outro, sem o que nos desumanizamos reciprocamente. (...) Isto é, sem comunicação não há humanização. A humanização depende de nossa capacidade de falar e ouvir, do diálogo com nossos semelhantes" 20 (p. 3).

"Nesse sentido, a Humanização supõe trocas de saberes [incluindo os dos pacientes e familiares] (...). Trata-se, então, de investir na produção de um novo tipo de interação entre os sujeitos que constituem os sistemas de saúde e deles usufruem, acolhendo tais atores e fomentando seu protagonismo" 19 (p. 8).

"Ampliar o diálogo entre os profissionais e os profissionais e a população...” 19 (p. 12).

A brevidade da menção à linguagem, à interação ou ao diálogo nos documentos talvez ateste para um campo ainda não tão largamente investigado na área da saúde no Brasil, qual seja, o da fala-em-interação. Para que se possa contribuir para a humanização da saúde, faz-se necessário que também se compreenda o impacto das políticas nos atendimentos em si, a partir do que está acontecendo nas interações do dia-a-dia entre cuidadores de saúde e pacientes. Isso é, faz-se necessário que se olhe para a comunicação em si entre profissionais da saúde e pacientes. É justamente dentro desse cenário de busca da humanização do Sistema Único de Saúde (SUS), com especial ênfase no processo de comunicação nos atendimentos à saúde, que este estudo se insere.

Este artigo tem como objetivos principais: (1) apresentar a abordagem teórico-analítica da Análise da Conversa aos estudos da área de saúde do Brasil; (2) refletir sobre como a Análise da Conversa pode revelar como questões macro (i.e., das Políticas Nacionais de Humanização) são traduzidas (ou não) para as práticas interacionais em nível mais micro (i.e., das relações interpessoais) e, assim, dar visibilidade às questões de linguagem e comunicação, apenas brevemente discutidas no Plano HumanizaSUS; e finalmente (3) analisar como um fenômeno interacional específico, o da "atribuição" (i.e., explicação à paciente sobre seu problema de saúde e/ou sintoma), pode descrever práticas cotidianas concretas de humanização nos atendimentos à saúde.

\section{Método}

\section{Introduzindo a Análise da Conversa às pesquisas em saúde no Brasil}

A abordagem metodológica a ser utilizada nesta investigação é a da Análise da Conversa de base etnometodológica 21,22,23,24,25, também conhecida como microssociologia das interações ou microetnografia. Conforme explicam Passuello \& Ostermann 26 , essa perspectiva se caracteriza por buscar compreender os métodos utilizados pelos próprios atores sociais enquanto desempenham seus diferentes papéis (por exemplo, de profissional da saúde e de paciente). Nessa abordagem, estuda-se a fala das pessoas propriamente dita - não seus pensamentos, intenções, emoções, crenças ou experiências de vida, assumidos como subjacentes à fala (e a serem expressos por meio dela). A perspectiva da Análise da Conversa entende a fala como uma forma de ação social - isto é, como uma forma de fazer coisas no mundo (como reclamar, discordar ou apresentar uma identidade em particular, como a de médico). Em outras palavras, investiga como as pessoas envolvidas na interação compreendem o que sua fala está fazendo, já que estas compreensões são disponibilizadas na própria fala 27. Dessa forma, a Análise da Conversa examina como os enunciados e outros comportamentos de um participante afetam o outro, de acordo com seqüências organizadas da fala 28 . 
A "fala de ocorrência natural", como a que se investiga aqui, pode ser definida como linguagem falada produzida de forma completamente independente de ações do pesquisador, seja ela a linguagem de conversas cotidianas ao telefone, de reuniões de trabalho ou de interações entre médicos e pacientes 29 . Na perspectiva proposta neste artigo, há um movimento intencional de afastamento de dados gerados com base em instrumentos (tais como as entrevistas post-factum) e de aproximação de interações mais reais, que acontecem na vida cotidiana. Por exemplo, consultas médicas obstétricas e ginecológicas, que constituem o objeto de estudo aqui proposto, acontecem diariamente, independentemente de um pesquisador ou uma pesquisadora dedicarse ao seu estudo.

As interações analisadas a partir da perspectiva da Análise da Conversa obrigatoriamente precisam ser gravadas. Isso porque, diferentemente de pesquisas que se centram no conteúdo das falas ou apenas no conteúdo do que foi dito, os estudos de Análise da Conversa atentam primordialmente para a forma como as coisas foram ditas. Sendo assim, métodos de coleta de dados que envolvam apenas observações com tomadas de notas não são suficientes. É somente com dados gravados em áudio (e em alguns casos, que não o desta pesquisa, também em vídeo) que podemos focalizar nos detalhes reais das interações, como pausas, falas co-construídas, falas simultâneas e outros fenômenos interacionais, aspectos estes que são tão caros a esta abordagem ${ }^{30}$. Assim que de posse das interações gravadas, dá-se início ao processo de transcrição dos dados. Observe a Tabela 1, que esclarece as convenções de transcrição encontradas nos excertos que se encontram na seção Análise e Discussão.

Cabe registrar aqui nossa consciência sobre o que foi descrito na literatura como "paradoxo do observador" 31 quando se pesquisa a fala natural: deseja-se observar como as pessoas conversam entre si quando não estão sendo observadas, mas isto se dá na presença de um gravador (um instrumento não "natural" às interações). Contudo, conforme já amplamente discutido em pesquisas sociolingüísticas, a tendência natural do ser humano é a de, depois de um período mínimo de tempo, "relaxar" e ignorar o fato de estar sendo gravado.

O método de gravações de interações entre profissionais da saúde e pacientes (inclusive entre profissionais em contextos de intervenção cirúrgica) é largamente utilizado em vários centros de pesquisa do mundo (vide, por exemplo, o Health Communication Research Center, na University of Cardiff, e o Public Health Sciences Department
Tabela 1

Convenções de transcrição encontradas nos excertos.

\begin{tabular}{lc}
\hline Item & Significado \\
\hline texto] & Falas sobrepostas \\
$(1.8)$ & Pausa \\
, & Entonação contínua \\
$\cdot$ & Entonação de ponto final \\
$?$ & Entonação de pergunta \\
$:$ & Alongamento de som \\
TEXTO & Fala com volume mais alto \\
Texto & Sílaba, palavra ou som acentuado \\
(Texto) & Dúvidas \\
XXXX & Texto inaudível \\
@@@ & Risada \\
$((T e x t o))$ & Comentários da transcritora \\
\hline
\end{tabular}

da University of Toronto). É freqüentemente reportado em pesquisas em periódicos da área da saúde, interessados na qualificação da comunicação entre profissionais e pacientes, tais como Communication \& Medicine: An Interdisciplinary Journal of Healthcare, Ethics and Society (Mouton de Gruyter), Journal of Health Communication: International Perspectives (Taylor \& Francis) e Medical Education (Blackwell).

\section{Coleta de dados e participantes}

Os dados primários da investigação proposta são provenientes de gravações em áudio de interações entre médicos ginecologistas e obstetras e pacientes de um posto do SUS de uma região metropolitana do Rio Grande do Sul. As interações foram gravadas entre março e dezembro de 2006 e contabilizam 144 ao todo. Não houve nenhuma participação ativa das pesquisadoras no momento das consultas, apesar de presentes nos atendimentos. Todas as interações gravadas foram transcritas conforme as convenções que são apresentadas na seção de análise deste artigo.

Para que fosse possível gravar as interações, as pacientes foram consultadas sobre seu consentimento antes do atendimento médico, na sala de espera, mediante termo por escrito (Termo de Consentimento Livre e Esclarecido), cujas cópias ficaram em seu poder. Os termos também foram utilizados com todos os médicos que participaram da pesquisa. Nas transcrições dos dados, toda e qualquer referência a nomes de pessoas, lugares e instituições é fictícia, de forma a garantir o anonimato dos participantes.

As pacientes participantes deste estudo são todas mulheres maiores de 18 anos, residentes 
no mesmo município em que está localizado o posto de saúde pesquisado. Os médicos que participaram desta pesquisa são cinco, quatro homens e uma mulher, todos das áreas de ginecologia e obstetrícia.

Cabe salientar que o projeto de pesquisa do qual deriva este estudo tramitou pelo Comitê de Ética em Pesquisa (CEP) da Universidade do Vale do Rio dos Sinos (UNISINOS), obtendo homologação por intermédio da Resolução $n^{o}$. 45/2005.

\section{Análise e discussão}

Na tradição de estudos da Análise da Conversa, conforme explica Heritage 32, o foco analítico (i.e., o que se analisará nos dados de interação coletados) é fortemente data-driven, i.e., determinado a partir de fenômenos que são evidenciados nos dados. Sendo assim, quando iniciamos a análise dos áudios e das transcrições das interações entre médicos e pacientes, não tínhamos um fenômeno interacional em mente. Com as transcrições em mãos, começamos a olhar para o que era recorrente nos dados. Foi a partir desse norte que chegamos ao foco analítico apresentado a seguir: a análise das atribuições produzidas pelas pacientes e de como os médicos reagem (ou não) a elas.

\section{Fenômeno interacional das atribuições} e suas conseqüências para a interação médico-paciente

As causas dos problemas de saúde dos pacientes são freqüentemente propostas por eles mesmos durante a consulta médica. Essas proposições que são externadas ao médico durante o atendimento são chamadas pelos estudiosos da comunicação médico-paciente de atribuições dos pacientes à causa do problema e/ou sintoma 33 . Exemplificamos o fenômeno da atribuição com o excerto 1 (Figura 1).

Nota-se que a paciente começa a descrever seus sintomas (em forma de reclamações, que podem ser observados das linhas 67-70 e 72, parte grifada) e depois passa a relacioná-los a uma condição hipotética, propondo que estes sintomas seriam causados por algum problema na bexiga (linha 73).

Muito mais do que crenças externadas, essas práticas dos pacientes realizam um trabalho socioestrutural na interação, que organiza o que é relevante em uma seqüência de turnos de fala, ou seja, organiza as ações subseqüentes dos interlocutores. Assim, na maioria dos casos, quando um paciente faz uma atribuição, ele está convidando seu interlocutor, neste caso, o médico, a considerar e avaliar a hipótese levantada ou a opinião emitida, conforme acontece a partir da linha 74 , momento em que o médico avalia o que foi dito pela paciente (a atribuição feita por ela). Nota-se que o médico não concorda com a paciente, elegendo outras causas possíveis para os sintomas que ela apresenta.

De uma forma geral, autores que relatam o fenômeno das atribuições em dados de interação entre médicos e pacientes mostram que ambos os interlocutores orientam-se para sua relevância nas diferentes fases da consulta médica ao produzirem-nas (tanto as atribuições quanto as respostas dadas a elas). Não podemos afirmar que isso constitui uma regra. Entretanto, em nossos dados, conforme discutido a seguir, foi observado que as pacientes procuram posicionar suas atribuições de maneira que possibilitem ao médico continuar a anamnese. Os médicos, por sua vez, parecem preferir responder às atribuições no momento do diagnóstico ou da prescrição do tratamento.

Gill \& Maynard 6 observaram em seus dados que há uma tendência à demora na resposta do médico às atribuições dos pacientes, tanto nas respostas que concordam quanto nas que discordam da opinião emitida pelos pacientes. Alguns estudos apontam que os pacientes, na maioria das vezes, não interrompem os médicos 34, o que poderia ser visto como uma orientação à assimetria que talvez exista entre os interagentes 11,35,36.

A literatura aponta casos em que os médicos não respondem, em nenhum momento da consulta, às atribuições feitas pelos pacientes, muitas vezes interrompendo a atribuição em curso para fazer perguntas que não têm relação com o que o paciente está dizendo. Frankel 37 adverte que esse fato é inquietante, pois o paciente tende a não apresentar a preocupação ou opinião novamente depois de ser interrompido. Há que se notar que, quando há informações que o paciente não conseguiu expressar, o diagnóstico médico corre muito mais riscos de ser rejeitado e, por conseguinte, pode não acontecer a adesão ao tratamento 38,39,40. Muitos autores afirmam que as informações ao alcance do médico, que surgem muitas vezes por intermédio dessas atribuições feitas pelos pacientes, são o meio para um diagnóstico mais apurado e para a satisfação do paciente 41,42 .

Veja-se a seguir algumas possíveis formas de atribuições encontradas em nossos dados, seu posicionamento durante a consulta e a resposta dos médicos a elas.

\section{- Pistas durante a anamnese}

Chamamos de pistas algumas atribuições que as pacientes fazem no momento da anamnese, com 


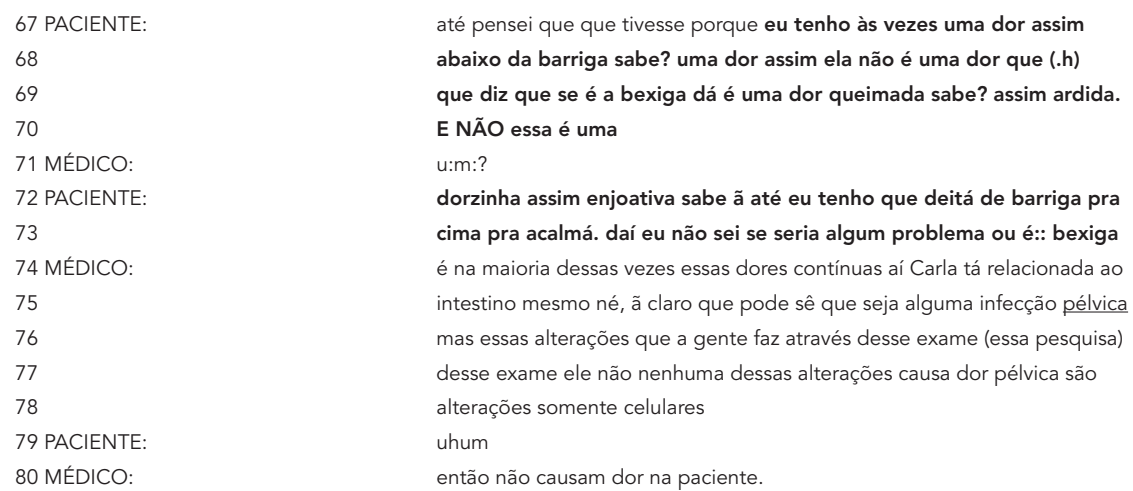

até pensei que que tivesse porque eu tenho às vezes uma dor assim

abaixo da barriga sabe? uma dor assim ela não é uma dor que (.h)

que diz que se é a bexiga dá é uma dor queimada sabe? assim ardida.

E NÃO essa é uma

u:m:?

dorzinha assim enjoativa sabe ã até eu tenho que deitá de barriga pra

cima pra acalmá. daí eu não sei se seria algum problema ou é:: bexiga

é na maioria dessas vezes essas dores contínuas aí Carla tá relacionada ao

intestino mesmo né, ã claro que pode sê que seja alguma infecção pélvica

mas essas alterações que a gente faz através desse exame (essa pesquisa)

desse exame ele não nenhuma dessas alterações causa dor pélvica são

alterações somente celulares

uhum

então não causam dor na paciente.

pouca ou nenhuma pressão para a resposta do médico, já que dificilmente ocorrem perguntas diretas nesta fase da consulta, mas sim comentários ou narrativas relacionadas aos sintomas. Segundo Gill \& Maynard 6, nesses casos mais indiretos de atribuições, o médico pode avaliar o que o paciente diz, mas não é compelido a isto.

Olharemos para o excerto 2 (Figura 2), no qual a paciente envolvida na interação acaba de relatar seus sintomas antigos (entre eles, corrimento vaginal) e o procedimento que outro médico adotara para tratá-la disto, bem como a injeção contraceptiva que este profissional havia lhe receitado. É em função de ela ainda estar com os sintomas que acontece essa nova consulta. Assim, a consulta médica já está na fase de anamnese no excerto 2 .

A paciente constrói uma atribuição fazendo uma reclamação (ou descrevendo um sintoma), qual seja, teve sangramento por vários dias consecutivos (linhas 84-85) quando tomou uma injeção (linhas 81-82, em "é que daí eu tomei essa injeção e...”). Essa circunstância reportada pela paciente pode ser vista como causa, pois tacitamente ela sugere que seu problema (sangramento anormal) ocorre em função da injeção contraceptiva que foi aplicada. Uma atribuição como essa pode representar uma pista ao médico dada pela paciente, já que não há uma pergunta explícita pressionando-o por uma resposta, mas a narração de um fato que pode vir a ser considerado ou não pelo interlocutor (no caso, o médico). É no excerto 3 (Figura 3), do mesmo atendimento, que encontramos a resposta do médico à atribuição sob análise.
O médico considera e avalia a sugestão (atribuição) da paciente ao cogitar o fato de a injeção causar o sangramento irregular (linhas 120-125). A característica da atribuição que contribuiu para um atraso na resposta do médico foi o seu posicionamento no momento da anamnese, permitindo a ele prosseguir, principalmente por não haver uma pressão por resposta no turno subseqüente (pelo fato de ser uma sugestão ou uma pista apenas). Chama a atenção também nessa interação a preocupação do médico em encontrar um método contraceptivo com o qual a paciente se sinta bem e que exista gratuitamente no posto de saúde (linha 140).

Há outro exemplo desse tipo de atribuição nos nossos dados (excerto 4; Figura 4).

No excerto 4, nota-se igualmente a ausência de pressão por uma resposta do médico. Na linha 7 , a paciente relata seus sintomas e nas linhas 9-10 explicita ao médico os lugares no corpo em que os sente, informando que a dor é no mesmo lugar em que no passado fora aplicada uma anestesia para cesariana. Na linha 85 , o médico demonstra ter percebido uma possível atribuição feita pela paciente anteriormente quando sugeriu uma relação de causa entre os sintomas expostos e a circunstância relatada (dor no lugar da anestesia), o que é refutado por ela (linha 86). Esse é mais um caso de atribuição em que o interlocutor pode tanto entendê-la como uma sugestão de causa para determinado sintoma (o que aconteceu) quanto como uma mera narrativa de circunstâncias. 


\begin{tabular}{|c|c|}
\hline 76 MÉDICO: & sempre usou camisinha? \\
\hline 77 & (2.0) \\
\hline 78 PACIENTE: & @@ ((riso de boca fechada - meio sem graça)) [é:::] \\
\hline 79 MÉDICO: & [nem] sempre é então \\
\hline 80 & tem que usá deprovera mesmo depoprove[ra ((anota)) \\
\hline 81 PACIENTE: & [TÁ MAS] é que daí eu tomei \\
\hline 82 & essa injeção e [mi]nha \\
\hline 83 MÉDICO: & [m] \\
\hline 84 PACIENTE: & menstruação veio praticamente:: (.) ã de uma semana veio: duas duas \\
\hline 85 & vezes que não veio a menstruação essa semana daí veio né tudo \\
\hline
\end{tabular}

Figura 3

Excerto 3 [POSTO070306EC].

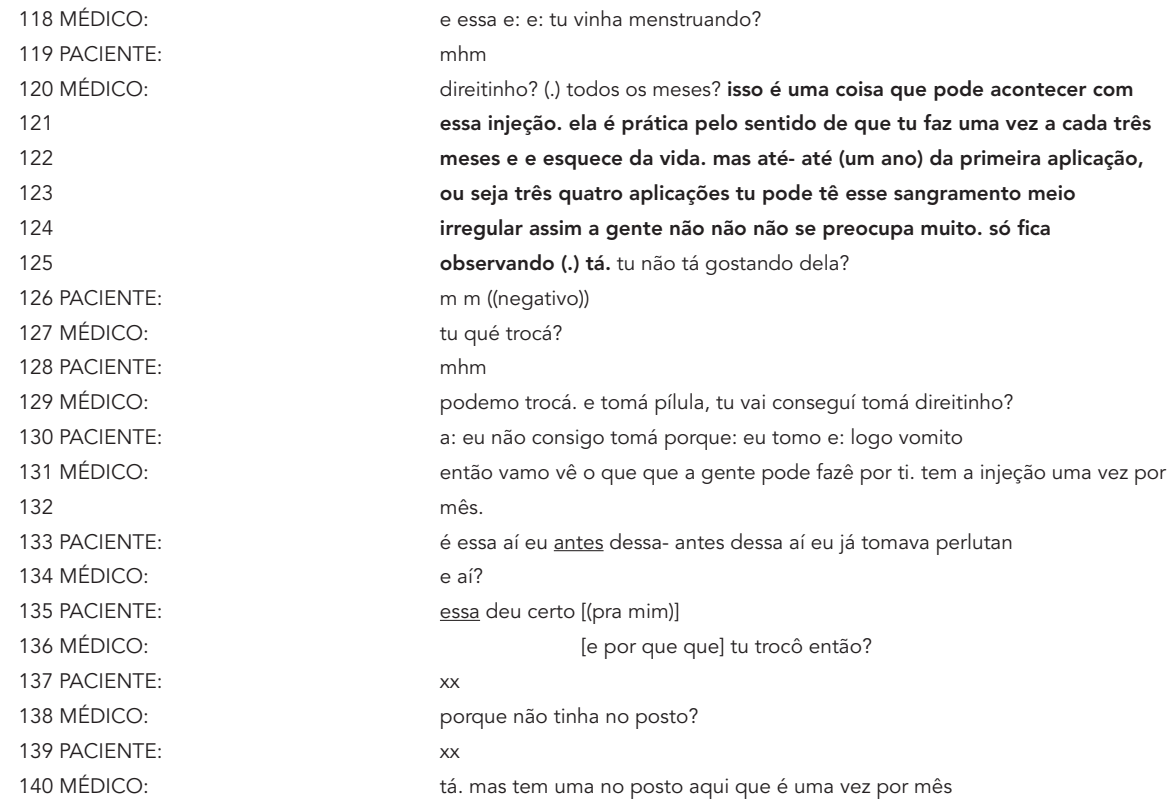

\section{- Informação a mais ao responder uma pergunta}

Também na anamnese, consoante salientam Gill \& Maynard 6, o paciente pode fazer uma atribuição em forma de informação suplemen- tar. Em outras palavras, o paciente provê mais conteúdo do que lhe foi solicitado pelo médico. Em função de poder ser interpretada como informação acessória, esse tipo de atribuição também não compele o médico a dar uma resposta imediata. Uma interação que retrata esse tipo 


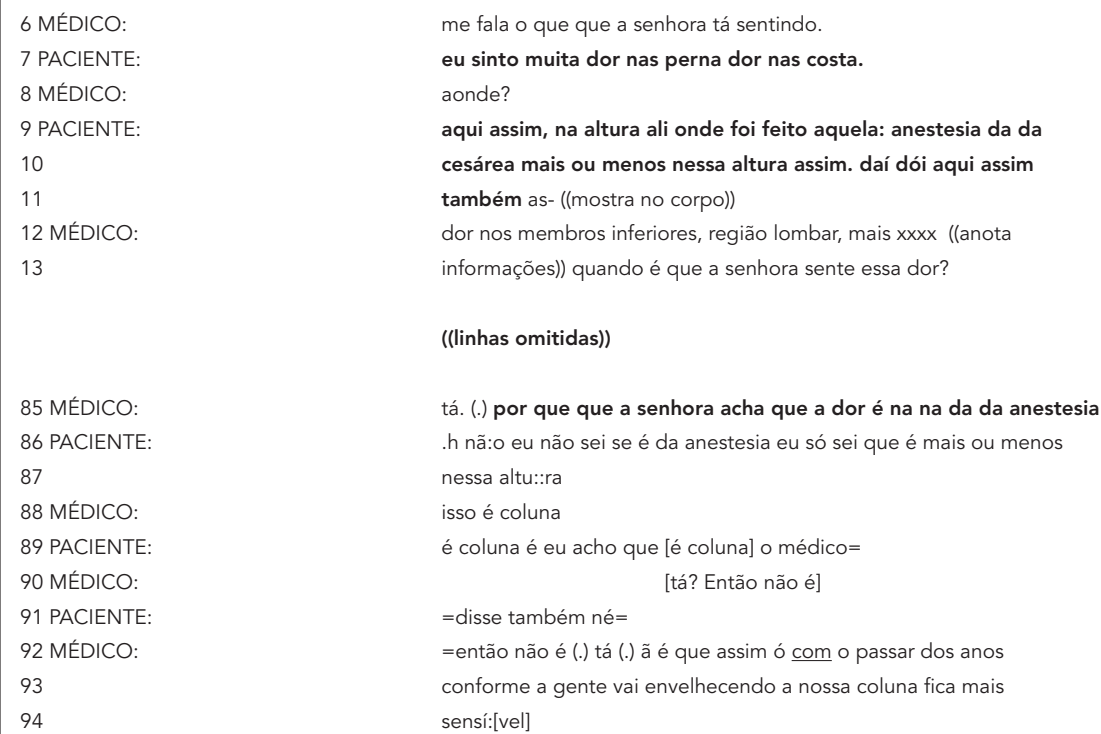

de ocorrência em nossos dados está no excerto 5 (Figura 5).

Nessa ocorrência de atribuição, a paciente está reclamando de sua menstruação estar constantemente atrasada e atribui o fato à sua idade (possível menopausa). Ao responder à pergunta feita pelo médico no turno anterior, a paciente produz a atribuição em formato de informação suplementar em seu turno de fala ("se é po:r causa do::: da minha ida:de”, linhas 95-96). Conforme discutido anteriormente, nesse tipo de atribuição o médico não se vê compelido a responder no próximo turno, e sim tem a opção de responder ou não. Assim como nas interações anteriores, ele não responde no turno de fala seguinte, mas o faz mais adiante, após outra atribuição, mas de diferente formato, conforme tratado a seguir.

\section{- Perguntas diretas aos médicos}

Conforme Gill \& Maynard 6 , atribuições feitas por meio de perguntas diretas "restringem as opções de resposta dos médicos, tanto que eles são compelidos a dar uma resposta, avaliando a atribuição" (p. 126-7). Bem mais raras, tendem a ocorrer apenas depois da anamnese, quando o médico já estaria apto a avaliar a possível causa do problema apresentado. Essas atribuições em forma de perguntas diretas são quase inexistentes em nossos dados. Ainda assim, há algumas ocorrências. O que temos representado no excerto 6 (Figura 6) é justamente uma pergunta direta compelindo o médico a dar uma resposta, alocada na fase do exame físico.

A interação é a mesma da qual advém o excerto 5 (Figura 5), mas, como mencionado anteriormente, médico e paciente estão agora envolvidos no exame físico. Nota-se que, para fazer uma pergunta direta à qual o médico pode responder discordando, a paciente atribui a terceiros a autoria da idéia sobre a possível causa da irregularidade menstrual (linha 115).

$\mathrm{Na}$ verdade, a paciente aqui parece reorganizar a sua atribuição (feita no excerto 5) em um formato mais direto - pergunta-, de maneira que desta vez o médico considere sua avaliação (linha 115). A pergunta fica evidente pelo uso de "né" - marcador discursivo que demanda uma resposta - e pela resposta do interlocutor (linha 116). Ainda assim, é interessante observar que a paciente remete a atribuição que faz a terceiros não identificados ("diz que”). O fato de a paciente colocar o assunto mais uma vez em pauta, por meio de uma atribuição de forma mais direta, parece demonstrar seu receio de ficar sem resposta. $\mathrm{O}$ médico responde à pergunta da paciente no 


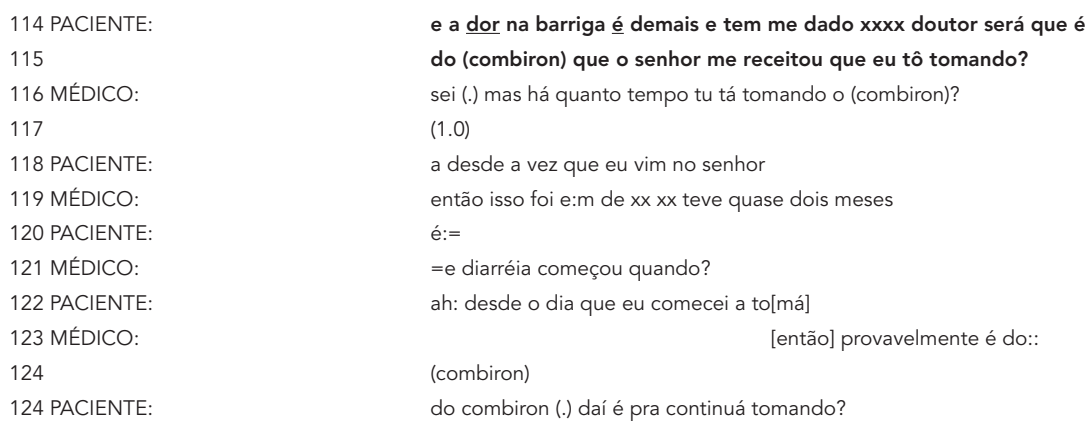

Nessa interação, a paciente faz uma atribuição e a imputa a uma terceira pessoa (linhas 121122). Nota-se que, para poder afirmar que o problema "é músculo" (linha 122), ela imputa a idéia ao seu marido, livrando-se da autoria e das conseqüências da afirmação (isto é, de ser avaliada, de poder ser corrigida e de causar desconforto ao afrontar o saber médico). Quanto ao posicionamento, a atribuição é feita pela paciente durante o exame físico, possibilitando ao médico imediatamente considerar seu conteúdo e já prover sua avaliação (linhas 123, 125 e 127). Dessa forma, o momento em que a atribuição foi feita (exame físico) favoreceu uma resposta imediata do médico. Além de prover uma resposta, observa-se uma forte preocupação também em tranqüilizar a paciente, inclusive elegendo outra causa possível para o problema (linhas 129-130 e 132).

A mesma estrutura ocorre na atribuição do excerto 9 (Figura 9).

A paciente, ao relatar seus sintomas, adiciona a informação de que consultou outro médico e ele sugerira pedra nos rins como causa do problema (linhas 28, 30, 32-34 e 36). Aqui, a paciente imputa àquele médico a responsabilidade de cogitar a idéia de pedra nos rins (o que é retomado por ela nas linhas 50 e 52). É interessante de se notar que ela utiliza um formato de atribuição que a livra da autoria e ao mesmo tempo dá mais validade à idéia que apresenta (pois é proveniente de um médico, não sua).

\section{Considerações finais}

Como visto neste artigo, a Análise da Conversa pode constituir uma produtiva abordagem ana- lítica para estudos qualitativos na área de saúde do Brasil, pois ela mostra as ações das pessoas por meio da linguagem. A partir da descrição do que acontece nas interações reais entre médicos e pacientes, via dados naturalísticos, podemos começar a entender melhor as dificuldades e os dilemas vivenciados pelos interlocutores e, por conseguinte, as suas estratégias comunicativas na busca do entendimento mútuo.

Acreditamos que o método microanalítico da Análise da Conversa pode revelar questões de ordem macro, como aquelas concernentes à humanização do SUS. Retomamos aqui parte do trecho da Política da Humanização do SUS, reproduzido no início deste artigo: “... a Humanização supõe trocas de saberes [incluindo os dos pacientes e familiares] (...). Trata-se, então, de investir na produção de um novo tipo de interação entre os sujeitos que constituem os sistemas de saúde e deles usufruem ...” 19 (p. 8). É exatamente isso que o artigo enfatiza, apresentando exemplos da prática médica: a importância da capacidade de falar e ouvir (na qual a troca de saberes está implicada), que pode ser a solução para grande parte dos problemas encontrados na comunicação entre médicos e pacientes.

A análise do fenômeno interacional das atribuições das pacientes à causa de seu problema, das maneiras pelas quais as atribuições são feitas e de como os médicos respondem (ou não) a elas pode fornecer subsídios para nossa compreensão de como a humanização na saúde pode também acontecer por meio da comunicação em si. Ainda que a literatura reporte casos em que os médicos não respondem às atribuições feitas por pacientes (inclusive interrompendo-os justamente no momento em que fazem uma atribuição), em 


\begin{tabular}{|ll|}
\hline 119 PACIENTE: & e aí me dói eu (.) toco ali dá agulhada \\
120 MÉDICO: & ãhã \\
121 PACIENTE: & me dá umas agulhada no seio (.) umas ferroada eu acho assim que \\
122 & é xx ou (.) sei lá (.) meu marido diz é músculo andressa @@ \\
123 MÉDICO: & vamo vê acho que xx \\
124 PACIENTE: & xxxxx \\
125 MÉDICO: & acho que não é mesmo nada da mama tá: \\
126 & $(5.0)$ \\
127 MÉDICO: & vamo vê uma ecografia da mama (pra ficá bem garantido) \\
128 & $(1.0)$ \\
129 MÉDICO: & mas pode sê também só por tu tá::.: (.) agora voltando a (.) o ciclo \\
130 & menstrual $[x x x]$ \\
131 PACIENTE: & [mhm] \\
132 MÉDICO: & tá (.) pode ficar tranqüila (.) não é nada grave \\
\hline
\end{tabular}

Figura 9

Excerto 9 [POSTO020506LA]

\begin{tabular}{|c|c|}
\hline 27 MÉDICO: & [di:z] \\
\hline 28 PACIENTE: & =eu tive:: (um-) (.) Le:mbra a do:r que eu fala:[:va, $]=$ \\
\hline 29 MÉDICO: & {$[\mathrm{mhm}]$} \\
\hline 30 PACIENTE: & =que começava nas co::sta e= \\
\hline 31 MÉDICO: & $=i::$ sto \\
\hline 32 PACIENTE: & .hh (.) um dia eu sente:i e levantei me:io de mal jeito e me deu \\
\hline 33 & mu:ito horrível a dor e eu fui pará no médico e e:le fez um exame \\
\hline 34 & de sangue e disse que tinha sangue na minha urina e podia sê-= \\
\hline 35 MÉDICO: & $=$ ã:: [uma pedra] $=$ \\
\hline 36 PACIENTE: & [pe:dra] \\
\hline 37 MÉDICO: & =no rim \\
\hline 38 PACIENTE: & é:. (.) aí:: \\
\hline 39 & (.) \\
\hline 40 MÉDICO: & [pediu eco?] \\
\hline 41 PACIENTE: & [me deu um] remé:dio- não. só me deu uns remédio eu tomei mas só: \\
\hline 42 & que: do:r volta e meia aparece aí: de no::vo= \\
\hline 43 MÉDICO: & =entã:o temos que fazer uma ecografia pra vê se é pedra no rim \\
\hline 44 & me:smo \\
\hline 45 PACIENTE: & {$[\mathrm{m}: \mathrm{h}: \mathrm{m}]$} \\
\hline 46 MÉDICO: & [pode] sê (2.0) ((escreve)) tem só dum la:do, \\
\hline 47 PACIENTE: & é:: só: desse lado aqui aí ele me:- me aper[tou]= \\
\hline 48 MÉDICO: & [isso] \\
\hline 49 PACIENTE: & $=e$ não doe:u mas daí ele me ba:teu com \\
\hline 50 & força na hora assim no::.:ssa aí:[: ele disse]= \\
\hline 51 MÉDICO: & [deu um pu:lo] \\
\hline 52 PACIENTE: & =que podia sê: né: \\
\hline 53 MÉDICO: & tá: \\
\hline 54 PACIENTE: & .h me deu remédio e tudo mas nã::o- não adianto:u nã:o \\
\hline 55 & por[que:::] \\
\hline 56 MÉDICO: & [conti]nua dolori:do \\
\hline 57 PACIENTE: & vo:Ita e meia eu tenho @ a do:r de novo \\
\hline
\end{tabular}


nossos dados, mesmo quando sutilmente apresentadas, os médicos são capazes de se orientar para estas atribuições e de fornecer respostas a elas, ainda que não sejam compelidos a fazê-lo. Em alguns casos em nossos dados, como no excerto 8 (Figura 8), além de o médico lidar com a atribuição feita pela paciente, existe uma preocupação em tranqüilizá-la, elegendo outras causas possíveis para o problema.

Nos dados que investigamos, observamos que as pacientes expressam de formas bastante complexas seu "saber" sobre possíveis causas para os seus problemas. As informações que as pacientes trazem por intermédio das atribuições são extremamente importantes, pois podem adiantar algo relevante ao médico, o que pode auxiliá-lo tanto na investigação como no diagnóstico mais seguro. Conforme discutido anteriormente, vários autores argumentam que as informações providas por intermédio das atribuições formuladas pelas pacientes são importantes para um diagnóstico apurado. Além disso, o tipo de resposta dos médicos às atribuições pode condicionar a adesão a tratamentos e a satisfação do paciente $37,38,39,40,41,42$.

Neste estudo, as pacientes parecem preferir as atribuições produzidas como informação acessória em turnos de fala (turnos que, normalmente, iniciaram como resposta a alguma pergunta médica) e as pistas (atribuições mais tácitas). Com isso, pode-se retomar, de forma mais assertiva, o que se apontou anteriormente, ou seja, que as pacientes se orientam para uma possível assimetria entre os interlocutores nesse tipo de interação.

Foi observado também que as pacientes, de um modo geral, alocam as atribuições na etapa de apresentação do problema e de anamnese. Contudo, não é nesse momento que elas têm maior sucesso em obter uma resposta dos médicos. Sua preferência em responder às atribuições feitas pelas pacientes está do momento do exame físico em diante. Finalmente, nos dados investigados, os médicos raramente deixam de avaliar uma atribuição trazida pela paciente.

Como vimos, as atribuições podem ser feitas desde formas muito sutis até formas mais explícitas. O fato de os médicos percebê-las (mesmo as mais sutis) e de preocuparem-se em dar uma resposta ou avaliação a elas reflete que estes profissionais estão interessados em disponibilizar um tratamento integral à pessoa. Ou seja, parece haver uma preocupação sua em "validar" o conhecimento trazido pela paciente para as interações. É exatamente isso que é humanizar por meio da linguagem: é dar a voz ao(à) paciente e validar seu saber e suas contribuições.

\section{Resumo}

Este estudo deriva de um projeto de pesquisa maior que investiga interações entre médicos e pacientes na saúde da mulher. Neste artigo, ao investigarmos dados naturalísticos, que consistem de 144 gravações, transcritas em sua íntegra, de interações face a face entre ginecologistas/obstetras e pacientes mulheres, propomos: (1) apresentar a abordagem teórico-analítica da Análise da Conversa aos estudos na área de saúde do Brasil; (2) refletir sobre como a Análise da Conversa pode revelar como questões macro (i.e., das Políticas Nacionais de Humanização) são traduzidas (ou não) para as práticas interacionais em nível mais micro (i.e., das relações interpessoais) e, assim, dar visibilidade às questões de linguagem e comunicação, apenas brevemente discutidas no Plano HumanizaSUS; e, finalmente, (3) analisar como um fenômeno interacional específico, o da "atribuição" (i.e., explicações voluntárias de pacientes sobre as causas de seus problemas de saúde elou sintomas), pode descrever práticas cotidianas concretas de humanização nos atendimentos à saúde.

Relações Médico-Paciente; Saúde da Mulher; Humanização da Assistência 


\section{Colaboradoras}

A. C. Ostermann concebeu o projeto maior do qual este estudo deriva e participou da coleta e análise dos dados e da redação do artigo. J. Souza participou da coleta, transcrição e análise dos dados e da redação do artigo. Ambas as autoras fizeram a revisão final do texto.

\section{Agradecimentos}

O presente estudo faz parte do projeto Gênero, Sexualidade e Violência: Uma Investigação Sociolingüística Interacional dos Atendimentos à Saúde da Mulher, coordenado por Ana Cristina Ostermann. Agradecemos ao Conselho Nacional de Desenvolvimento Científico e Tecnológico (CNPq), à Fundação de Amparo à Pesquisa do Estado do Rio Grande do Sul (FAPERGS) e ao Ministério da Saúde pelo apoio obtido por meio de bolsa de produtividade (processo $\mathrm{n}^{\circ}$. 311288/2006-5) concedida à primeira autora, e pelos auxílios à pesquisa obtidos através dos editais MS/CNPq/FAPERGS 06/2006 (processo $\mathrm{n}^{\circ}$. 0700767) e CNPq 61/2005 Hum/Soc/Aplic (processo $\mathrm{n}^{\circ}$. 400625/2006-7).

\section{Referências}

1. Vaitsman J, Andrade GRB. Satisfação e responsividade: formas de medir a qualidade e a humanização da assistência à saúde. Ciênc Saúde Coletiva 2005; 10:599-613.

2. Costa AM. Integralidade na atenção e no cuidado à saúde. Saúde Soc 2004; 13:5-15.

3. Traverso-Yépez M, Morais NA. Reivindicando a subjetividade dos usuários da Rede Básica de Saúde: para uma humanização do atendimento. Cad Saúde Pública 2004; 20:80-8.

4. Caprara A, Franco ALS. A relação paciente-médico: para uma humanização da prática médica. Cad Saúde Pública 1999; 15:647-54.

5. Ostermann AC, Silva CR. Contribuições dos estudos de fala em interação para a compreensão dos atendimentos à saúde da mulher. In: Anais do Seminário Internacional Fazendo Gênero. Florianópolis: Editora Mulheres; 2006. p. 1-7.
6. Gill VT, Maynard DW. Explaining illness: patients' proposals and doctors' responses. In: Heritage J, Maynard DW, editors. Communication in medical care: interaction between primary care physicians and patients. Cambridge: Cambridge University Press; 2006. p. 115-50.

7. Collins S, Britten N, Ruusuvuori J, Thompson A, editors. Patient participation in health care consultations. Maidenhead: Open University Press; 2007.

8. Maynard DW, Heritage J. Conversation analysis, doctor-patient interaction and medical communication. Med Educ 2005; 39:428-35.

9. Pomerantz A, Rintel ES. Practices for reporting and responding to test results during medical consultations: enacting the roles of paternalism and independent expertise. Discourse Studies 2004; 6:9-26. 
10. Silverman D. Going private: ceremonial forms in a private oncology clinic. Sociology 1984; 18:191-204.

11. West C. Not just doctors' orders. In: Coates J, editor. Language and gender: a reader. Oxford: WileyBlackwell; 1998. p. 328-53.

12. West C. When the doctor is a 'lady'. In: Coates J, editor. Language and gender: a reader. Oxford: Wiley-Blackwell; 1998. p. 396-412.

13. Potter J, Hepburn A. Discursive psychology as a qualitative approach for analysing interaction in medical settings. Med Educ 2005; 39:338-44.

14. Pudlinski C. Doing empathy and sympathy: caring responses to troubles telling on a peer support line. Discourse Studies 2005; 7:267-88.

15. Madureira PR, Capitani EM. Qualidade da atenção em rede hierarquizada: a interface serviço/paciente. Cad Saúde Pública 1990; 6:158-74.

16. Tanaka OY, Espírito Santo ACG. Avaliação da qualidade da atenção básica utilizando a doença respiratória da infância como traçador, em um distrito sanitário do Município de São Paulo. Rev Bras Saúde Matern Infant 2008; 8:325-32.

17. Oliveira DF, Arieta CEL, Temporini ER, Kara-José N. Quality of health care: patient satisfaction in a university hospital. Arq Bras Oftalmol 2006; 69:731-6.

18. Durães-Pereira MBBB, Novo NF, Armond JE. A escuta e o diálogo na assistência ao pré-natal, na periferia da zona Sul, no Município de São Paulo. Ciênc Saúde Coletiva 2007; 12:465-76.

19. Ministério da Saúde. Política nacional de humanização - HumanizaSUS. Brasília: Ministério da Saúde; 2004.

20. Ministério da Saúde. Programa nacional de humanização do atendimento hospitalar - PNHAH. Brasília: Ministério da Saúde; 2000.

21. Barnes R. Conversation analysis: a practical resource in the health care setting. Med Educ 2005; 39:113-5.

22. Drew P, Chatwin J, Collins S. Conversation analysis: a method for research into interactions between patients and health-care professionals. Health Expect 2001; 4:58-70.

23. Have PT. Doing conversation analysis. London: Sage Publications; 1999

24. Wetherell M. Positioning and interpretative repertoires: conversation analysis and post-structuralism in dialogue. Discourse \& Society 1998; 9:387-412.

25. Wooffitt R. Conversation analysis and discourse analysis: a comparative and critical introduction. London: Sage Publications; 2005.

26. Passuello C, Ostermann AC. Aplicação da análise da conversa etnometodológica em entrevista de seleção: considerações sobre o gerenciamento de impressões. Estud Psicol (Natal) 2007; 12:243-51.

27. Wilkinson S, Kitzinger C. Constructing identities: a feminist conversation analytic approach to positioning in action. In: Harré R, Moghaddam A, editors. The self and the others: positioning individuals and groups in personal, political and cultural contexts. New York: Praeger/Greenwood; 2003. p. 157-80.
28. Heritage J, Maynard DW. Communication in medical care: interaction between primary care physicians and patients. Cambridge: Cambridge University Press; 2006.

29. Potter J. Discourse analysis as a way of analysing naturally occurring data. In: Silverman D, editor. Qualitative research: theory, method and practice. London: Sage Publications; 2004. p. 200-21.

30. Silverman D. Interpreting qualitative data: methods for analyzing talk, text and interaction. London: Sage Publications; 2001

31. Labov W. The study of language in its social context. In: Pride J, Holmes J, editors. Sociolinguistics. New York: Penguin; 1972. p. 180-202.

32. Heritage J. Garfinkel and ethnomethodology. Cambridge/New York: Polity Press; 1984.

33. Gill VT. Doing attributions in medical interaction: patient's explanations for illness and doctors responses. Soc Psychol Q 1998; 61:342-60.

34. Gill VT, Halkowski T, Roberts F. Accomplishing a request without making one: a single case analysis of a primary care visit. Text 2001; 21:55-81.

35. Hydén LC, Mishler EG. Language and medicine. Annual Review of Applied Linguistics 1999; 19:17492.

36. Caprara A, Rodrigues J. A relação assimétrica médico-paciente: repensando o vínculo terapêutico. Ciênc Saúde Coletiva 2004; 9:139-46.

37. Frankel RM. Clinical care and conversational contingencies: the role of patients' self diagnosis in medical encounters. Text 2001; 21:83-111.

38. Halpern J. Empathy and patient-physician conflicts. J Gen Intern Med 2007; 22:696-700.

39. Ferreira EC, Ribeiro MMF, Leal SS. Praticando a relação médico-paciente III: efeito terapêutico da consulta. Clínica Médica 2002; 2:51-64.

40. Carvalho CV, Duarte DB, Merchán-Hamann E, Bicudo E, Laguardia J. Determinantes da aderência à terapia anti-retroviral combinada em Brasília, Distrito Federal, Brasil, 1999-2000. Cad Saúde Pública 2003; 19:593-604.

41. Beckman HB, Frankel RM. Training practitioners to communicate effectively in cancer care: it is the relationship that counts. Patient Educ Couns 2003; 50:85-9.

42. West C, Frankel RM. Miscommunication in medicine. In: Coupland N, Wiemann JM, Giles H, editors. Miscommunication and problematic talk. London: Sage Publications; 1991. p. 166-94.

43. Goffman E. On face-work: an analysis of ritual elements in social interaction. Psychiatry: Journal for the Study of Interpersonal Processes 1955; 18:213-31.

Recebido em 11/Jun/2008

Versão final reapresentada em 04/Fev/2009

Aprovado em 16/Fev/2009 